\title{
Seasonality in digestion and rumen metabolism in red deer (Cervus elaphus) fed on a forage diet
}

\author{
BY D. O. FREUDENBERGER ${ }^{1 *}$, K. TOYAKAWA ${ }^{1 \dagger}$, T. N. BARRY ${ }^{1} \S$, A. J. BALL ${ }^{1} \ddagger$ \\ AND J. M. SUTTIE \\ ${ }^{1}$ Department of Animal Science, Massey University, Palmerston North, New Zealand, \\ ${ }^{2}$ AgResearch Invermay, Mosgiel, New Zealand
}

(Received 27 January 1993 - Revised 5 July 1993 - Accepted 19 July 1993)

\begin{abstract}
Six adult castrated male red deer (Cervus elaphus), fitted with rumen cannulas, were offered chaffed lucerne hay ad lib. during winter and summer, with voluntary food intake (VFI) being respectively 59 and $89 \mathrm{~g}$ dry matter intake (DMI)/kg bodyweight 0.75 per $\mathrm{d}$. The same animals were also offered the same feed during summer, with intake restricted to that of winter VFI. The apparent digestibility of gross energy (0.60) or fibre (0.41) and the total capacity (volume) of the rumen were unaffected by season or level of intake. Relative to winter $a d$ lib. feeding, $N$ retention, total rumen pool size (DM + water), rumen pool size as a proportion of capacity, and rumen total volatile fatty acid (VFA) pool size were increased during summer ad lib. feeding. Relative to winter ad lib. feeding, $\mathrm{N}$ retention, rumen ammonia irreversible loss rate (IRL), total rumen pool size, rumen pool size as a proportion of capacity, and rumen ammonia and total VFA pool sizes were also increased during summer restricted feeding. Rumen lignin fractional disappearance rate (FDPR) was lower in summer than in winter, and there was a nonsignificant trend for rumen fractional outflow rate (FOR) of liquid to follow the same trend. Molar proportions of acetate and propionate were unaffected by season, proportions of $n$-butyrate were slightly higher in summer, and proportions of iso-butyrate and iso-valerate were higher for summer restricted than for winter ad lib. feeding. When intakes were equalized there were no seasonal changes in rate of rumen water outflow, net rumen water balance or intestinal water absorption. It is concluded that there is a seasonal change in rumen physiology in red deer during summer causing increased total rumen pool size (DM + water), an increase in rumen ammonia production and pool size, and an increase in rumen total VFA pool size which are all independent of the increase in VFI. The increased total rumen pool size in the summer restricted group may indicate an increased mean retention time (MRT) of digesta in the rumen. MRT for particulate matter was calculated to be 29.2 and $34.8 \mathrm{~h}$ during winter and summer respectively. This, together with increased rumen ammonia production, may function to maintain rumen fibre digestion when VFI normally increases during summer. The increased rumen VFA pool size may indicate increased VFA production during summer, in the same way as ammonia IRL was increased.
\end{abstract}

Red deer: Digestion: Rumen pool size: Ammonia production: Rumen outflow

Deer from temperate regions show a marked seasonality in voluntary feed intake (VFI) and body growth, with lower values in winter and higher values in summer (Milne et al. 1978; Barry et al. 1991). The summer increase in VFI is also associated with a marked increase in rumen digesta load, but there is hypertrophy of the rumen tissues (Sibbald \& Milne 1993). The objectives of the present investigation were to establish whether the red deer

* Present address: CSIRO Division of Wildlife and Ecology, PO Box 84, Lyneham, ACT, Australia.

$\dagger$ Present address: Laboratory of Animal Science, Faculty of Agriculture, Hirosaki University, Hirosaki, Japan.

$\ddagger$ Present address: Department of Animal Science, University of New England, Armidale, Australia.

$\S$ For reprints. 
(Cervus elaphus) also shows seasonal changes in digestive function and to establish whether any seasonal changes were independent of seasonal changes in VFI. Criteria investigated were apparent digestibility, rumen pool size and fractional outflow rate (FOR), N excretion and retention, rumen volatile fatty acid (VFA) concentration, pool size and molar proportions and rumen $\mathrm{NH}_{3}$ production, here defined as the irreversible loss rate (IRL).

\section{MATERIALS AND METHODS \\ Experimental design}

One experiment with three treatments was conducted, each with the same format and using the same animals and feed from the same batch. The first treatment was conducted at ad $l i b$. intake during winter, the second at ad lib. intake in summer and the third during summer with intake restricted to the same level as recorded for winter ad lib. intake (summer restricted). Each experimental period comprised a 2 week adjustment period to the diet followed by a $7 \mathrm{~d}$ collection period to measure the apparent digestibility of the feed. An indigestible marker was then infused into the rumen for a further $5 \mathrm{~d}$ and ${ }^{15} \mathrm{~N}$-labelled $\mathrm{NH}_{4} \mathrm{Cl}$ was added for the last $2 \mathrm{~d}$ during treatments 1 and 3 , to determine rumen FOR and rumen $\mathrm{NH}_{3}$ IRL respectively. Rumen fluid samples were removed on $3 \mathrm{~d}$ during the infusion to determine the concentrations of VFA and $\mathrm{NH}_{3}$, and to check plateau attainment for ${ }^{15} \mathrm{~N}$ enrichment of $\mathrm{NH}_{3}$. Rumen contents were removed by baling at the end of the infusion to determine pool sizes and ${ }^{15} \mathrm{~N}$ enrichment of $\mathrm{NH}_{3}$.

\section{Animals, housing and diets}

Six castrated hand-reared male red deer aged 3-5 years were used. All were fistulated in the rumen and fitted with a permanent rubber cannula $(83 \mathrm{~mm}$ i.d.), were well accustomed to the experimental conditions, and were kept in metabolic crates similar to those described by Milne et al. (1978). There was no leakage from the rumen cannulas during any of the three treatment periods. The crates were housed in a well ventilated building with artificial light set at $9 \mathrm{~h}$ light-15 h dark during the winter period and $15 \mathrm{~h}$ light $-9 \mathrm{~h}$ dark during the two summer periods. Water was provided $a d$ lib. and a multi-mineral salt block (Dominion Salt, Blenheim, NZ) was in each feed bin at all times. Good quality lucerne (Medicago sativa) hay, all from the same batch, was chopped into $10-30 \mathrm{~mm}$ lengths and given in each period at hourly intervals from overhead feeders.

\section{Treatments}

During the first period (winter ad lib., June 1990) feed was offered ad lib. (1.2 times the previous day's consumption) for 2 weeks. During the subsequent weeks feed was offered at 1.035 of voluntary feed intake (VFI) in order to minimize diet selectivity. During the second period (summer ad lib., Feb 1991) feed was offered exactly as described for winter ad lib. feeding. During the final period (summer restricted; March 1991) feed was offered at 1.035 of the winter VFI on a $\mathrm{g}$ dry matter $(\mathrm{DM}) / \mathrm{kg}$ bodyweight $(\mathrm{W})^{\mathbf{0} 7 \overline{5}}$ per $\mathrm{d}$ basis, as liveweight had increased slightly from winter to summer.

\section{Marker infusion}

The inert fluid marker Cr-EDTA was prepared by the method of Binnerts et al. (1968) and adjusted to a $\mathrm{pH}$ of $6 \cdot 5-8 \cdot 0$. The Cr-EDTA was made up to 201 with a final $\mathrm{Cr}$ concentration of $2 \mathrm{mg} / \mathrm{g}$ of solution. Following a priming dose of $40 \mathrm{~g}$ into the rumen, the marker solution was continuously infused into the rumen for $5 \mathrm{~d}$ at a rate of $23-25 \mathrm{~g} / \mathrm{h}$. The exact infusion rate was determined for each animal. The infusion was administered by a 
peristaltic pump (PLG-multipurpose pump; Desaga, Heidelberg, Germany). ${ }^{15} \mathrm{~N}$-labelled $\mathrm{NH}_{4} \mathrm{Cl}$ solution ( 99.0 atoms \% excess, $0.5 \mathrm{mg} / \mathrm{g}$ of infusate; Amersham, UK) was added to the Cr-EDTA solution during the last $45 \mathrm{~h}$ of infusion.

\section{Sample collection}

Feed, feed refusals and faeces were weighed daily during the $7 \mathrm{~d}$ collection period and a sub-sample $\left(20 \%\right.$ of each material) was taken and stored at $-20^{\circ}$. Another daily subsample of each material was taken for duplicate determination of DM in a forced draught oven $\left(100^{\circ}\right)$. Urine was weighed daily from buckets containing sufficient $\mathrm{H}_{2} \mathrm{SO}_{4}(250 \mathrm{ml} / \mathrm{l})$ to maintain $\mathrm{pH}$ below $3 \cdot 5$. After the collection periods all frozen subsamples were bulked within animals, mixed thoroughly and re-sampled, then freeze dried, ground through a $1 \mathrm{~mm}$ mesh sieve (Wiley Mill, USA) and used for analysis.

Rumen fluid samples for VFA, $\mathrm{NH}_{3}-\mathrm{N}$ concentration and $\mathrm{Cr}$ determinations were taken twice daily (10.00 and 15.00 hours) on $3 \mathrm{~d}$ during the infusion period, and also at rumen emptying. During the infusion period the samples were taken from a tube that passed through the bung of the rubber cannula and was attached to a perforated brass cylinder covered with nylon mesh ( 80 micron aperture; Swiss Screens, Sydney, Australia). The length of the sampling tube was adjusted so that the sampling apparatus hung within the middle of the rumen. The first $20 \mathrm{ml}$ of rumen fluid was discarded at each sampling time. Rumen fluid was also obtained when the rumen was emptied by squeezing mixed digesta through a nylon mesh ( 80 micron aperture). Fluid for $\mathrm{NH}_{3}-\mathrm{N}$ and VFA analysis was acidified, deproteinized and centrifuged as described by Domingue et al. (1991 a).

The rumens were emptied while the deer were slightly sedated with xylazine (Rompun, Bayer AG, Germany). The rumen contents were weighed, mixed thoroughly and subsampled before returning the warmed digesta back to the rumen. The procedure took 15-20 min per animal and the animals remained standing throughout.

Rumen fluid was sampled for ${ }^{15} \mathrm{~N}$ enrichment at 23,35 and $45 \mathrm{~h}$ after commencing the infusion. This final sample $(45 \mathrm{~h})$ was taken when the rumen was emptied and its contents mixed. These rumen fluid samples were immediately acidified with $0.1 \mathrm{ml}$ concentrated $\mathrm{H}_{2} \mathrm{SO}_{4}$, centrifuged, and the supernatant stored at $-20^{\circ}$.

\section{Rumen capacity}

Rumen capacity (i.e. volume) was determined by inflating, with warm water, a balloon placed inside the emptied rumen as described by Domingue et al. (1992). This measurement was made only at the end of the winter $a d$ lib. and summer restricted periods.

\section{Analytical}

Samples of feed, feed refused, faeces and rumen digesta were analysed for cell wall constituents by the detergent method (not including the amylase) of Robertson \& Van Soest (1980), total $\mathrm{N}$ by the Kjeldahl method, gross energy by adiabatic bomb calorimetry (Gallenkamp Autobomb; Loughborough, Leics.), and organic matter by ashing overnight at $550^{\circ}$. Total $\mathrm{N}$ of urine was also determined by the Kjeldahl method. Cr concentration was determined by atomic absorption spectrometry. $\mathrm{NH}_{3}-\mathrm{N}$ and VFA were determined as described by Domingue et al. (1991 $a$ ).

${ }^{15} \mathrm{~N}-\mathrm{NH}_{3}$ was isolated from rumen fluid samples by the use of an ion-exchange column as modified from Read et al. (1982). Acidified rumen fluid was centrifuged at $9000 \mathrm{rev} . / \mathrm{min}$, and a $5 \mathrm{ml}$ portion was adjusted to $\mathrm{pH} 5.5-7.5$ with $1 \mathrm{M}-\mathrm{NaOH}$; Na-K cation exchange resin (Dowex 50, 100-200 mesh) suspension $(2 \mathrm{ml})$ was then added to the rumen fluid preparation and mixed for $15 \mathrm{~min}$. The supernatant was discarded and the resin was washed three times with deionised water. $\mathrm{NH}_{3}$ was eluted off the resin with $2.5 \mathrm{M}-\mathrm{KHSO}_{4}$ 
and this supernatant was evaporated to dryness. ${ }^{15} \mathrm{~N}$ enrichment of the resulting ammonium bisulphate was determined by mass spectrometry $( \pm 0.0002$ atoms $\%$; Waikato Stable Isotope Unit; Hamilton, New Zealand).

\section{Calculations}

Fractional outflow rate (FOR) and fractional disappearance rates (FDPR) from the rumen were calculated as shown below. The method used to determine FOR is the continuous infusion and total sampling procedure (Faichney, 1975).

$$
\begin{aligned}
\text { FOR }(\% \text { per } \mathrm{h}) & =\frac{\text { Marker infusion rate }(\mathrm{mg} / \mathrm{h}) \times 100}{\text { Rumen pool size }(\mathrm{mg})}, \\
\text { FDPR }(\% \text { per } \mathrm{h}) & =\frac{\text { Intake }(\mathrm{g} / \mathrm{h}) \times 100}{\text { Rumen pool size }(\mathrm{g})}
\end{aligned}
$$

Cr-EDTA was used to calculate rumen liquid FOR and lignin to calculate particulate FOR; in the latter case, faeces lignin excretion was substituted for infusion rate in equation (1), on the assumption that there was minimal post-ruminal degradation. Rumen pool sizes were determined when the rumens were emptied.

The IRL of $\mathrm{NH}_{3}-\mathrm{N}$ was expressed as the rate (mass/unit time) at which $\mathrm{NH}_{3}-\mathrm{N}$ leaves the rumen pool and does not return during the experimental period (Nolan \& Leng, 1972):

$$
\operatorname{IRL}(\mathrm{mg} \mathrm{N} / \mathrm{d})=\frac{\text { infusion rate of }{ }^{15} \mathrm{~N}(\mathrm{mg} / \mathrm{d})}{\text { enrichment at plateau of rumen } \mathrm{NH}_{3}-\mathrm{N} \text { with }{ }^{15} \mathrm{~N}}
$$

Plateau enrichment used in equation (3) was determined from samples taken when the rumen was emptied, after $45 \mathrm{~h}$ of ${ }^{15} \mathrm{~N}$ infusion. Rumen $\mathrm{NH}_{3}-\mathrm{N}$ outflow was calculated by multiplying rumen $\mathrm{NH}_{3}-\mathrm{N}$ pool size by the FOR of $\mathrm{Cr}$-EDTA. The outflow of water from the rumen was calculated as rumen liquid pool $(\mathrm{g}) \times$ FOR of Cr-EDTA (d). Rumen water balance was calculated as the difference between rumen water outflow and total water intake $(\mathrm{g} / \mathrm{d})$; it represents the combined total of salivary secretion and net inflow of water across the rumen wall. Apparent absorption of water from the intestines was calculated as the difference between rumen water outflow and faeces water output.

\section{Statistical analysis}

Mean values and the standard errors of differences of the means (SED) are presented. The values for $\mathrm{NH}_{3}-\mathrm{N}$ and VFA are the means of seven observations/animal, since there were no significant differences $(P>0 \cdot 1)$ between the day, time of day or type of sampling (rumen emptying or by sampling apparatus). Univariate analysis of variance of repeated measures (Gill, 1986; Genstat Statistical Software, 1988) was used to remove between-animal variation before analysing for seasonal differences. Means were compared by the method of least significant difference (Snedecor \& Cochran, 1980).

\section{RESULTS}

Chemical composition of the lucerne chaff fed showed only minor variation between the three feeding periods (Table 1). Mean liveweight of the deer during summer ad lib. feeding $(109 \cdot 7 \mathrm{~kg})$ was significantly higher $(P<0.001)$ than during winter ad lib. feeding $(96.1 \mathrm{~kg})$. Mean liveweight during summer restricted feeding $(104.5 \mathrm{~kg})$ was also significantly higher than during winter ad lib. feeding $(P<0 \cdot 01)$. VFI of all the constituents measured (Table 2 ) were much higher for summer ad lib. than for winter ad lib. feeding $(P<0 \cdot 001)$, whilst 
Table 1. Composition ( $\mathrm{g} / \mathrm{kg}$ dry matter $(D M)$ ) of chopped lucerne (Medicago sativa) hay fed to rumen fistulated red deer (Cervus elaphus) stags during winter and summer ad lib. and summer restricted periods*

\begin{tabular}{lccc}
\hline \hline Feeding group... & Winter ad lib. & Summer ad lib. & Summer restricted \\
\hline Organic matter & 907 & 891 & 877 \\
Neutral detergent fibre & 407 & 380 & 382 \\
Acid detergent fibre & 279 & 256 & 252 \\
Lignin & 58 & 55 & 54 \\
Total N & $32 \cdot 5$ & $32 \cdot 8$ & $35 \cdot 6$ \\
Gross energy (kJ/g DM) & $19 \cdot 0$ & $18 \cdot 2$ & $18 \cdot 0$ \\
\hline
\end{tabular}

* For details of treatments, see p. 490.

Table 2. Voluntary intakes and digestible intakes of dry matter $(D M)$, organic matter $(O M)$ and fibre (neutral detergent residue) with their apparent digestibilities, of chopped lucerne (Medicago sativa) hay fed to rumen fistulated red deer (Cervus elaphus)

(Mean values and standard error of the difference between means for six animals)

\begin{tabular}{|c|c|c|c|c|}
\hline Feeding group* $\ldots$ & Winter $a d l i b$. & Summer ad lib. & Summer restricted & SED \\
\hline \multicolumn{5}{|l|}{ Voluntary intake } \\
\hline $\mathrm{DM}\left(\mathrm{g} / \mathrm{kg} \mathrm{W}^{0.75}\right.$ per $\left.\mathrm{d}\right)$ & $58 \cdot 7$ & $88 \cdot 6$ & $61 \cdot 3$ & 1.90 \\
\hline$(\mathrm{g} / \mathrm{d})$ & 1773 & 2988 & 1989 & $96 \cdot 3$ \\
\hline $\mathrm{OM}\left(\mathrm{g} / \mathrm{kg} \mathrm{W} \mathrm{W}^{0 \cdot 75}\right.$ per $\left.\mathrm{d}\right)$ & $53 \cdot 2$ & 76.5 & $56 \cdot 1$ & 2.55 \\
\hline$(\mathrm{g} / \mathrm{d})$ & 1607 & 2576 & 1825 & $89 \cdot 5$ \\
\hline Fibre $\left(\mathrm{g} / \mathrm{kg} \mathrm{W}^{0.75}\right.$ per $\left.\mathrm{d}\right)$ & $22 \cdot 9$ & $30 \cdot 7$ & $24 \cdot 3$ & $1 \cdot 07$ \\
\hline \multicolumn{5}{|l|}{ Apparent digestibility } \\
\hline DM & $0 \cdot 618$ & 0.606 & 0.577 & $0 \cdot 0124$ \\
\hline $\mathrm{OM}$ & 0.640 & 0.632 & 0.642 & $0 \cdot 0198$ \\
\hline Fibre & $0 \cdot 436$ & 0.394 & 0.421 & 0.0337 \\
\hline Gross energy & 0.609 & 0.600 & 0.614 & 0.0207 \\
\hline
\end{tabular}

W, bodyweight.

* For details of procedures, see pp. $490-491$.

the objective of maintaining intake of the summer restricted group to the same level as the winter ad lib. group on a per $\mathrm{kg} \mathrm{W}^{0.75}$ basis was attained. Apparent digestibility of DM was lower for summer restricted than for either winter or summer ad lib. feeding $(P<0.05)$. None of the treatments significantly affected apparent digestibility of organic matter (OM), energy and fibre.

None of the treatments affected total rumen capacity (Table 3). Relative to winter ad lib. feeding, summer ad lib. feeding resulted in greater rumen pool size per $\mathrm{kg} \mathrm{W}^{0.75}$ of both DM and liquid $(P<0.01)$ and markedly increased total (DM and liquid) and DM pools as a proportion of total rumen capacity $(P<0.01)$. Relative to winter ad lib. feeding, summer restricted feeding also increased total rumen pool size per $\mathrm{kg} \mathrm{W}^{0.25}(P<0.01)$, total rumen pool size as a proportion of rumen capacity $(P<0.05)$ and DM pool as a proportion of capacity $(P<0 \cdot 05)$. Differences in rumen pool sizes between summer restricted and winter $a d$ lib. feeding were smaller in magnitude than the differences between summer $a d l i b$. and winter ad lib. feeding. When values were expressed as $\mathrm{kg} / \mathrm{kg}$ dry matter intake (DMI), summer restricted feeding increased total and liquid rumen pool sizes $(P<0.01)$ relative to winter ad lib. feeding, with summer $a d$ lib. feeding being intermediate. 
Table 3. Rumen capacity, pool sizes and fractional outflow rates of $C r$-EDTA and lignin from the rumen of red der (Cervus elaphus) stags fed on chopped lucerne (Medicago sativa) hay $\dagger$

(Mean values and standard error of the difference between means for six animals)

\begin{tabular}{|c|c|c|c|c|}
\hline Feeding group ... & Winter ad lib. & Summer $a d l i b$. & Summer restricted & SED \\
\hline Rumen capacity $\left(\mathrm{g} \mathrm{H}_{2} \mathrm{O} / \mathrm{kg} \mathrm{W}^{0 \cdot 75}\right)$ & 487 & 509 & 447 & $31 \cdot 3$ \\
\hline \multicolumn{5}{|l|}{ Rumen pool size $\left(\mathrm{g} / \mathrm{kg} \mathrm{W}^{0 \cdot 75}\right)$} \\
\hline Dry matter (DM) & 35.9 & $57 \cdot 1$ & $39 \cdot 2$ & 2.90 \\
\hline Liquid & 207 & 336 & 258 & 11.9 \\
\hline Total* & 243 & 392 & 297 & $13 \cdot 2$ \\
\hline \multicolumn{5}{|l|}{ Rumen pool size $(\mathrm{kg} / \mathrm{kg} \mathrm{DMI})$} \\
\hline DM & 0.624 & 0.646 & 0.638 & 0.0478 \\
\hline Liquid & 3.58 & 3.80 & $4 \cdot 25$ & $0 \cdot 171$ \\
\hline Total* & $4 \cdot 20$ & $4 \cdot 45$ & $4 \cdot 89$ & 0.195 \\
\hline \multicolumn{5}{|l|}{ Rumen pool: rumen capacity } \\
\hline DM pool:capacity & 0.0745 & $0 \cdot 1136$ & 0.0873 & 0.0059 \\
\hline Total pool : capacity & 0.496 & $0 \cdot 776$ & 0.670 & 0.039 \\
\hline \multicolumn{5}{|l|}{ Fractional disappearance rate $(\%$ per $h)$} \\
\hline Lignin & $3 \cdot 43$ & $2 \cdot 90$ & $2 \cdot 84$ & 0.349 \\
\hline \multicolumn{5}{|l|}{ Fractional outflow rate $(\%$ per $h)$} \\
\hline Cr-EDTA & $16 \cdot 3$ & ND & $12 \cdot 4$ & $2 \cdot 52$ \\
\hline Lignin & $3 \cdot 15$ & $2 \cdot 67$ & $2 \cdot 78$ & 1.000 \\
\hline Cr-EDTA/lignin & $5 \cdot 37$ & ND & $4 \cdot 50$ & $0 \cdot 440$ \\
\hline DM of rumen digesta $(\%)$ & $14 \cdot 7$ & $14 \cdot 6$ & $13 \cdot 2$ & 0.79 \\
\hline
\end{tabular}

W, Bodyweight; ND, not determined; DMI, dry matter intake.

* DM + liquid pools.

$\dagger$ For details of procedures, see pp. $490-492$.

Table 4. Nitrogen $(N)$ excretion and retention in rumen fistulated red deer (Cervus elaphus) fed on chopped lucerne (Medicago sativa) hay*

(Mean values and standard error of the difference between means for six animals)

\begin{tabular}{|c|c|c|c|c|}
\hline Feeding group... & Winter ad lib. & Summer ad lib. & Summer restricted & SED \\
\hline \multicolumn{5}{|l|}{$\mathrm{N}$ fluxes $\left(\mathrm{g} \mathrm{N} / \mathrm{kg} \mathrm{W}^{0.75}\right.$ per $\left.\mathrm{d}\right)$} \\
\hline Intake & 1.98 & 3.03 & $2 \cdot 19$ & $0 \cdot 068$ \\
\hline Faecal excretion & $0 \cdot 50$ & 0.86 & 0.64 & 0.029 \\
\hline Urinary excretion & $1 \cdot 18$ & 1.53 & $1 \cdot 14$ & $0 \cdot 061$ \\
\hline \multicolumn{5}{|l|}{$\mathrm{N}$ balance } \\
\hline $\mathrm{g} \mathrm{N} / \mathrm{kg} \mathrm{W}^{0.75}$ per $\mathrm{d}$ & $0 \cdot 30$ & 0.63 & $0 \cdot 41$ & $0 \cdot 047$ \\
\hline $\mathrm{g} \mathrm{N} / 100 \mathrm{~g}$ DMI & $0 \cdot 51$ & 0.71 & 0.67 & $0 \cdot 075$ \\
\hline $\mathrm{g} \mathrm{N} / 100 \mathrm{~g} \mathrm{~N}$ intake & $15 \cdot 1$ & $20 \cdot 7$ & $18 \cdot 7$ & $2 \cdot 18$ \\
\hline Apparent $N$ digestibility & $0 \cdot 749$ & 0.714 & $0 \cdot 708$ & 0.1000 \\
\hline Urine excretion (proportion $\mathrm{N}$ intake) & 0.598 & 0.507 & 0.521 & 0.0207 \\
\hline
\end{tabular}

W, Body weight; DMI, dry matter intake.

* For details of procedures, see pp. 490-492.

Rumen lignin FDPR (Table 3) tended to be similar for both summer groups and lower than for the winter ad lib. group, with the difference between summer restricted and winter ad lib. groups attaining significance at $P<0 \cdot 1$. When data for both summer groups were pooled, the combined summer value for rumen lignin fractional disappearance rate differed from the winter ad lib. group at $P=0.078$. 
Table 5. Concentration of ammonia, pool size and irreversible loss of ${ }^{15} N$ in the rumen of red deer (Cervus elaphus) fed on chopped lucerne (Medicago sativa) hay*

(Mean values and standard error of the difference between means for six animals)

\begin{tabular}{|c|c|c|c|c|}
\hline Feeding group $\ldots$ & Winter ad lib. & Summer ad lib. & Summer restricted & SED \\
\hline \multicolumn{5}{|l|}{ Ammonia } \\
\hline Concentration (mg NH $\mathrm{NH}_{3}-\mathrm{N} / \mathrm{l}$ ) & 193 & 191 & 218 & $19 \cdot 7$ \\
\hline Pool size $\left(\mathrm{g} \mathrm{NH}_{3}-\mathrm{N}\right)$ & $1 \cdot 22$ & ND & 1.83 & 0.094 \\
\hline Pool size (mg/g N intake) & $20 \cdot 4$ & ND & 23.9 & 1.07 \\
\hline Outflow (mg N/g N intake) & $77 \cdot 3$ & ND & $75 \cdot 4$ & $12 \cdot 20$ \\
\hline Irreversible loss rate ( $\mathrm{mg} \mathrm{N} / \mathrm{g} \mathrm{N}$ intake) & 522 & ND & 649 & $29 \cdot 1$ \\
\hline
\end{tabular}

ND, not determined

* For details of procedures, see pp. 490-492.

Rumen FOR of both Cr-EDTA and lignin also tended to be lower for summer restricted than for winter ad lib. feeding, but the differences did not attain significance $(P>0 \cdot 10)$. Although the combined summer value for rumen lignin FOR was lower than for the winter ad lib. value $(2.73$ v. $3 \cdot 15 \% / \mathrm{h})$, the difference was not significant $(P=0.15)$ due to the variation encountered.

Apparent $\mathrm{N}$ digestibility $(P<0.05)$ and urinary $\mathrm{N}$ excretion (expressed as a proportion of $\mathrm{N}$ intake; $P<0.01$ ) were lower for both summer treatments than for the winter ad lib. treatment (Table 4). $\mathrm{N}$ retention of deer fed ad lib. during summer was higher than that of deer fed ad lib. during winter, regardless of whether this was expressed per $\mathrm{kg} \mathrm{W}^{0.75}$ $(P<0.01)$ or per $100 \mathrm{~g}$ DMI or $\mathrm{N}$ intake $(P<0.05)$. N retention of deer on summer restricted feeding was intermediate, and significantly different from winter ad lib.-fed deer when expressed per $\mathrm{kg} \mathrm{W}^{0.75}(P<0.05)$ and per $100 \mathrm{~g}$ DMI $(P<0 \cdot 10)$. Rumen $\mathrm{NH}_{3}$ concentration and rumen $\mathrm{NH}_{3}$ outflow were not affected by season of feeding (Table 5). Rumen $\mathrm{NH}_{3}{ }^{15} \mathrm{~N}$-enrichment attained plateau values before $45 \mathrm{~h}$ of infusion in both the summer and winter periods, and rumen $\mathrm{NH}_{3}$ pool size $(P<0.05)$ and IRL $(P<0.01)$ were both higher during summer restricted than during winter $a d l i b$. feeding $(+50$ and $24 \%$ respectively).

Drinking water and total water intakes were higher for both summer ad lib. $(P<0.001)$ and summer restricted $(P<0.01)$ than for winter ad lib. feeding (Table 6). However, there were no differences between winter $a d l i b$. and summer restricted in net rumen water balance, rumen water outflow, intestinal water absorption, and faecal water efflux. Lower urinary efflux during summer $(P<0.01)$ probably reflected greater body evaporative water losses at this time.

Relative to winter ad lib., summer ad lib. feeding elevated rumen total VFA concentration $(P<0.05)$ and pool size (per $\mathrm{kg} \mathrm{W}^{0.75}, P<0.001$; per $\left.100 \mathrm{~g} \mathrm{DMI}, P<0.05\right)$, and slightly increased the molar proportions of $n$-butyrate $(P<0 \cdot 01$; Table 7$)$. These effects were still evident when summer VFI was reduced to the same level as winter VFI, but of a lower magnitude, with VFA concentration $(P<0 \cdot 1)$ and pool size (per $\mathrm{kg} \mathrm{W}^{0 \cdot 75}$ and per $100 \mathrm{~g}$ DMI, $P<0.05$ ) of summer restricted being higher than for winter ad lib., and proportions of $n$-butyrate being higher for summer restricted than for winter ad lib. $(P<0.01)$. Molar proportions of iso-butyrate and iso-valerate were greater for summer restricted than for winter ad lib. feeding $(P<0.05)$. 
Table 6. Water fluxes and net rumen water balance in red deer (Cervus elaphus) fed on chopped lucerne (Medicago sativa) hay*

(Mean values and standard error of the difference between means for six animals)

\begin{tabular}{|c|c|c|c|c|}
\hline Feeding group... & Winter $a d l i b$. & Summer ad lib. & Summer restricted & SED \\
\hline \multicolumn{5}{|l|}{ Water fluxes $\left(\mathrm{g} / \mathrm{kg} \mathrm{W}^{0 \cdot 75}\right.$ per $\left.\mathrm{d}\right)$} \\
\hline Drinking influx & 173 & 271 & 232 & $14 \cdot 4$ \\
\hline Total influx $\dagger$ & 175 & 275 & 233 & $14 \cdot 5$ \\
\hline Net rumen water balance + & 635 & ND & 529 & $127 \cdot 4$ \\
\hline Rumen outflow§ & 807 & ND & 761 & $126 \cdot 2$ \\
\hline Intestinal absorption\| & 765 & ND & 711 & $125 \cdot 4$ \\
\hline Faecal efflux & 42 & 68 & 50 & $4 \cdot 4$ \\
\hline Urinary efflux & 103 & 94 & 97 & 18 \\
\hline Faecal dry matter & 0.345 & 0.328 & 0.356 & 0.0207 \\
\hline
\end{tabular}

W, Bodyweight; ND, not determined.

* For details of procedures, see pp. $490-492$.

$\dagger$ Drinking water + water in feed.

$\$$ Rumen outflow-total influx = salivary secretions + net flux of water across the rumen wall.

$\S$ Rumen liquid pool $\times$ FOR $(/ d)$ of Cr-EDTA.

\| Apparent absorption; rumen water outflow-faecal water efflux.

Table 7. Concentration and molar proportions of volatile fatty acids (VFA) in the rumen of red deer (Cervus elaphus) fed on chopped lucerne (Medicago sativa) hay*

(Mean values and standard error of the difference between means for six animals)

\begin{tabular}{|c|c|c|c|c|}
\hline Feeding group... & Winter ad lib. & Summer $a d l i b$. & Summer restricted & SED \\
\hline \multicolumn{5}{|l|}{ Total VFA } \\
\hline Concentration $(\mathrm{mmol} / \mathrm{l})$ & $81 \cdot 9$ & $96 \cdot 5$ & $91 \cdot 0$ & $5 \cdot 47$ \\
\hline Pool size $\left(\mathrm{mmol} / \mathrm{kg} \mathrm{W}^{0.75}\right)$ & $16 \cdot 9$ & $32 \cdot 4$ & $23 \cdot 6$ & $2 \cdot 23$ \\
\hline (mmol $/ 100 \mathrm{~g} \mathrm{DMI})$ & $29 \cdot 2$ & $36 \cdot 7$ & 38.5 & 2.95 \\
\hline \multicolumn{5}{|l|}{ Molar proportion (mol\%) } \\
\hline Acetate & $71 \cdot 4$ & $69 \cdot 7$ & $70 \cdot 2$ & $0 \cdot 45$ \\
\hline Propionate & $18 \cdot 4$ & $18 \cdot 4$ & $17 \cdot 7$ & $0 \cdot 31$ \\
\hline$N$-Butyrate & 6.4 & $7 \cdot 7$ & $7 \cdot 5$ & $0 \cdot 31$ \\
\hline Iso-butyrate & $1 \cdot 37$ & 1.59 & $1 \cdot 70$ & 0.170 \\
\hline$n$-Valerate & 1.01 & 1.07 & $1 \cdot 11$ & 0.066 \\
\hline Iso-valerate & 1.38 & 1.62 & 1.79 & 0.181 \\
\hline Acetate:propionate ratio & 3.89 & $3 \cdot 81$ & 3.98 & 0.079 \\
\hline
\end{tabular}

W, Bodyweight; DMI, dry matter intake.

* For details of procedures, see pp. 490491.

\section{DISCUSSION}

All temperate deer species show seasonality (Barry et al. 1991), which is manifest as annual cycles of VFI, body growth, plasma hormone concentrations, reproductive activity and coat type. The VFI cycle reaches a peak in summer and a trough in winter. Relative to the large amount of information on these aspects, there have been few studies on seasonality in digestive function in deer. Mean retention time (MRT) in the whole alimentary tract is shorter for red deer (Cervus elaphus) and Japanese sika deer (Cervus nippon) than for domesticated sheep, and this is associated with slightly lower apparent digestibility of organic matter and fibre in deer (Milne et al. 1978; Katoh et al. 1991). Domingue et al. $(1991 b)$ showed that rumen liquid FOR (i.e. 1/MRT) was faster for red deer (16\% per h) 
than for sheep and goats $(10 \%$ per $\mathrm{h})$, and that this occurred in both summer and winter. The present study has shown an increase in total rumen pool size and in the rumen pool sizes of liquid, $\mathrm{NH}_{3}$ and VFA in summer compared with winter which are independent of VFI. The most logical explanation for the increased total and liquid pool sizes in summer restricted compared with winter ad lib.-fed deer is reduced rumen FOR of the liquid and particulate phases in summer. Although these did decline in this direction for both $\mathrm{Cr}$ EDTA and lignin in the present study, the differences did not attain significance. However, rumen lignin fractional disappearance rate (FDPR) was shown to be lower in summer than in winter, and is related to fractional outflow rate (FOR) and fractional degradation rate (FDR) by equation 4 :

$$
\mathrm{FDPR}=\mathrm{FOR}+\mathrm{FDR} \text {. }
$$

In the present study there was minimum degradation of lignin (Table 3), with FDPR being of similar magnitude to FOR, but less variable to measure, thus suggesting that rumen outflow rate of particulate matter must have been slower in summer than in winter.

In the present study, apparent rumen MRT of particulate matter (1/lignin FDPR) can be calculated as 29.2 and $34.8 \mathrm{~h}$ for winter and summer. Similar values of $28.8 \mathrm{~h}$ for winter and $36.1 \mathrm{~h}$ for summer can be calculated from Domingue $e t$ al. $(1991 \mathrm{~b})$ for true particulate MRT (1/lignin FOR), for red deer fed on a similar diet to that used in the present study. As total rumen volume (i.e. capacity) did not change between seasons, this may be a digestive adaptation that deer have evolved to increase rumen MRT (and hence time for microbial attack) under conditions where VFI increases in summer, thus ensuring that apparent digestibility does not decline with the summer increase in VFI.

This is the first study to show a seasonal increase in the rate of rumen $\mathrm{NH}_{3}$ production, and we have shown this to be independent of changes in VFI. This may be one of the components responsible for maintaining fibre digestion as VFI increases during summer, especially if the diet is high in lignin and low in N, such as the Agrostis-Festuca and heather diets fed by Milne et al. (1978). The mechanism of the increased rumen $\mathrm{NH}_{3}$ IRL presumably involves increased recycling of $\mathrm{N}$ into the rumen during summer, as dietary $\mathrm{N}$ intakes were similar in the winter and summer restricted groups. Iso-butyrate and isovalerate are formed from deamination of valine and leucine in the rumen (Van Soest, 1982). The increased concentration of these compounds in the rumen fluid of summer restricted deer also suggests that protein degradation rate may be faster in summer than in winter, also contributing to the greater $\mathrm{NH}_{3}$ IRL.

It seems that deer show a seasonal increase in rumen total VFA pool size during summer that is independent of changes in VFI. As rumen liquid volume was greater in summer than in winter, contributing causes may be longer residence time of material in the rumen during summer, giving more time for fermentation activity, and perhaps a greater rate of fermentation. A combination of the two could potentially result in a greater rate of VFA production during summer, as observed for rumen $\mathrm{NH}_{3}$ production (i.e. IRL), and this should be studied in future experiments.

Increased $N$ retention occurred from winter to summer during ad lib. feeding, as also found by Domingue et al. (1991a), but in the present study a component of this was independent of changes in VFI. It may be due to increases during late spring and summer in plasma concentrations of growth hormone (GH) and IGF-1 (Suttie et al. 1989) and prolactin (Brinklow \& Forbes, 1982) and insulin secretory variables as evidenced by insulin clearance after the glucose tolerance test (IVGTT) (McMahon et al. 1992). The hormonal milieu in spring-summer of high GH, IGF-1 and prolactin and a large, rapid insulin response to the IVGTT followed by a rapid clearance of insulin and glucose is conducive, generally, to the effective deposition of protein. Whether this suitable hormonal milieu is a consequence of, or the cause of, the changes in VFI and rumen dynamics is not known. 
The present study raises the possibility that many of the changes seen in deer, as seasonal growth rates vary, are endogenous and not simply a consequence of VFI. This may mean that seasonal cycles of growth and VFI, although functionally and intimately related, are not strictly identical.

Domingue et al. (1991a) observed a seasonal cycle in water metabolism in red deer, with increased rumen outflow, net rumen water balance (net inflow from saliva and diffusion) and intestinal absorption occurring in summer compared with winter. However, there were no differences in rumen water outflow and intestinal water absorption between winter and summer restricted feeding in the present study, showing these effects to be due only to increased VFI during summer. Net rumen water balance in fact decreased slightly in the summer restricted group, to counteract the increase from drinking at this time.

It is concluded that red deer show a seasonal cycle of rumen digestive function, with increased total rumen pool size, increased pool sizes of liquid, VFA and $\mathrm{NH}_{3}$ and increased rumen $\mathrm{NH}_{3}$ production in summer compared with winter, that are independent of changes in VFI. These indicate increased rumen retention time in summer and may function to maintain rumen fibre digestion rates when VFI normally increases during summer. The increased VFA pool size may indicate increased rumen VFA production during summer in the same way that rumen $\mathrm{NH}_{3}$ IRL is increased.

Mr G. S. Purchas, Dr A. M. Ataja and Miss P. S. Parker are thanked for assistance with animal feeding and animal measurements, and Miss R. A. Watson, Mr D. A. Hamilton and Mrs Ai Hua are thanked for laboratory analyses. Mr W. Müller, CSIRO Biometrics Unit, is thanked for statistical advice.

\section{REFERENCES}

Barry, T. N., Suttie, J. M., Milne, J. A. \& Kay, R. N. B. (1991). Control of food intake in domesticated deer. In Physiological Aspects of Digestion and Metabolism in Ruminants, pp. 385 402 [T. Tsuda, Y. Sasaki and R. Kawashima, editors). San Diego: Academic Press.

Binnerts, W. T., van't Klooster, A. T. \& Frens, A. M. (1968). Soluble chromium indicator measured by atomic absorption in digestion experiments. Veterinary Record $\mathbf{8 2}, 470$.

Brinklow, B. R. \& Forbes, J. M. (1982). Prolactin infusion causes increased nitrogen retention in lambs in continuous darkness. Proceedings of the Nutrition Society 42, 38A.

Domingue, B. M. F., Dellow, D. W., Wilson, P. R. \& Barry, T. N. (1991a). Nitrogen metabolism, rumen fermentation, and water absorption in red deer, goats and sheep. New Zealand Journal of Agricultural Research 34, 391-400.

Domingue, B. M. F., Dellow, D. W., Wilson, P. R. \& Barry, T. N. (1991 b). Comparative digestion in deer, goats and sheep. New Zealand Journal of Agricultural Research 34, 45-53.

Domingue, B. M. F., Wilson, P. R., Dellow, D. W. \& Barry, T. N. (1992). Effects of subcutaneous melatonin implants during long daylength on voluntary feed intake, rumen capacity and heart rate of red deer (Cervus elaphus) fed on a forage diet. British Journal of Nutrition 68, 77-88.

Faichney, G. J. (1975). The use of markers to partition digestion within the gastro-intestinal tract of ruminants. In Digestion and Metabolism of the Ruminant, pp. 277-291 [I. W. McDonald and A. C. I. Warner, editors]. Armidale: University of New England Publishing Unit.

Genstat Statistical Software (1988). Genstat 5. Statistics Dept, Rothamsted Experimental Station, Hertfordshire, UK.

Gill, J. L. (1986). Repeated measurement: Sensitive tests for experiments with few animals. Journal of Animal Science 63, 943-954.

Katoh, K., Kajita, Y., Odashima, M., Ohta, M. \& Sasaki, Y. (1991). Passage and digestibility of lucerne (Medicago sativa) hay in Japanese sika deer (Cervus nippon) and sheep under restricted feeding. British Journal of Nutrition 66, 399405 .

McMahon, C. D., Corson, 1. D., Johnstone, P. D., Stuart, S. K., Veenvliet, B. A. \& Suttie, J. M. (1992). Seasonal insulin response to an intravenous challenge in red deer stags. A possible role in the seasonal growth pattern? Proceedings of the Australian Endocrinology Society 35, 164.

Milne, J. A., MacRae, J. C., Spence, A. M. \& Wilson, S. (1978). A comparison of the voluntary intake and digestion of a range of forages at difference times of the year by the sheep and the red deer (Cervus elaphus). British Journal of Nutrition 40, 347-357. 
Nolan, J. V. \& Leng, R. A. (1972). Dynamic aspects of ammonia and urea metabolism in sheep. British Journal of Nutrition 27, 177-194.

Read, W. W. C., Harrison, R. A. \& Halliday, D. (1982). A resin-based method for the preparation of molecular nitrogen for ${ }^{15} \mathrm{~N}$ analysis from urinary and plasma components. Analytical Biochemistry 123, 249-254.

Robertson, J. B. \& Van Soest, P. J. (1980). The detergent system of analysis and its application to human foods. In The Analysis of Dietary Fibre in Foods, pp. 123-158 [W. P. T. James and O. Theander, editors]. New York: Marcel Dekker.

Sibbald, A. M. \& Milne, J. A. (1993). Physical characteristics of the alimentary tract in relation to seasonal changes in voluntary food intake by the red deer. Journal of Agricultural Science, Cambridge 120, $99-102$.

Snedecor, G. W. \& Cochran, W. G. (1980). Statistical Methods, 7th ed. Ames, lowa: Iowa State University Press.

Suttie, J. M., Fennessy, P. F., Corson, I. D., Laas, F. J., Crosbie, S. F., Butler, J. H. \& Gluckman, P. D. (1989).

Pulsatile growth hormone, insulin-like growth factors and antler development in red deer stags. Journal of Endocrinology 121, 351-360.

Van Soest, P. J. (1982). Nutritional Ecology of the Ruminant. Corvallis, Oregon, USA: O \& B Books. 